\title{
Life cycle variation and the genetic structure of nematode populations
}

\author{
MICHAEL S. BLOUIN*†, JIE LIU \& RALPH E. BERRY \\ $\dagger$ Department of Zoology and $\ddagger$ Department of Entomology, Oregon State University, Corvallis, OR, 97331, U.S.A.
}

\begin{abstract}
Few data are available on population genetic structure in nematode species, and little of the available data allows direct comparison of the genetic structures of species having different life cycles. Here we use mtDNA sequence data to describe the genetic structure of a heterorhabditid nematode, and compare results to published data on other nematode species. Heterorhabditis marelatus is a parasite of soil-dwelling insects. Its life cycle and local ecology should result in small effective population sizes and restricted gene flow. As predicted, H. marelatus shows much lower mtDNA diversity within populations and over the species as a whole, and has a much more strongly subdivided population structure, than parasites of mobile vertebrate hosts. From data such as these we can begin to generalize about the effects of life cycle variation on genetic structure in different nematode species.
\end{abstract}

Keywords: effective size, gene flow, Heterorhabditis, mitochondrial DNA, ND4.

\section{Introduction}

We still know little about the population genetic structure of most parasite species, the exceptions being mostly species of medical or agricultural importance (e.g. Lymbery et al., 1990; Tibayrenc et al., 1991; Day et al., 1992; Anderson et al., 1995; Blouin et al., 1995; Dybdahl \& Lively, 1996; Babiker \& Walliker, 1997; Blair et al., 1997). This oversight is surprising because data on genetic structure are necessary for understanding important evolutionary processes such as adaptation to host defences, host-race formation, speciation, and the evolution of resistance to drugs or vaccines. Nematodes in particular are a grossly understudied taxon. Even though nematodes are one of the most speciesrich, ecologically diverse and economically important taxa, we have information on genetic structure for only a handful of nematode species, and almost all of these are human or agricultural parasites (recently reviewed in Anderson et al., 1998). Virtually nothing is known of the genetic structure of any free-living nematode species (including Caenorhabditis elegans). Thus, more comparative studies on genetic structure in nematode species are clearly needed. Indeed, Hughes et al. (1997) specifically called for more data on nematodes in their recent review of patterns of population differentiation in different taxa.

*Correspondence. E-mail: blouinm@bcc.orst.edu

(c) 1999 The Genetical Society of Great Britain.
Parasitic nematodes display a wide variety of life cycles and life histories. For example, they parasitize almost all groups of plants and animals, and occur in virtually every marine, terrestrial and freshwater habitat. Their breeding system can be obligately or facultatively amphimictic (two distinct sexes), parthenogenetic or hermaphroditic. They range from highly host-specific to undiscriminating, and vary in the presence or absence of free-living stages and intermediate hosts. How this diversity of life cycles influences genetic structure in different nematode species is unknown. We currently have too few comparative data from which to make any but the simplest predictions.

What is needed are comparative studies of the genetic structure of nematode species that differ in key features of the life cycle, using similar sampling designs and the same molecular markers. For example, using mtDNA sequence data Blouin et al. (1995) showed that host mobility has a large effect on genetic structure in trichostrongylid species that parasitize different species of ruminants. We see the effect of differences in population size in comparisons between trichostrongylids and Ascaris species (Anderson et al., 1998). Both have similar life cycles (simple, one-host, obligately outcrossing, with a mobile vertebrate host), but differ by orders of magnitude in population sizes, and correspondingly in levels of both mtDNA and nuclear intron diversity. In contrast, plant parasitic nematodes having a predominantly parthenogenetic mode of reproduction show much lower overall mtDNA diversity than either 
Ascaris or the trichostrongylids (Meloidogyne spp.; Hugall et al., 1994). Here we used mtDNA sequence data to describe the genetic structure of a species that parasitizes soil-dwelling insects.

\section{Study species and predictions about genetic structure}

Heterorhabditis marelatus is in the family Heterorhabditidae, one of two main families of entomopathogenic nematodes (Gaugler \& Kaya, 1990). Entomopathogenic nematodes are obligate parasites of soil-dwelling insects. Infective juveniles (IJs) of these species actively seek insect hosts in soil. After penetrating a host, IJs release a symbiotic gut bacterium (Photorhabdus spp.) that rapidly kills the host, usually within $24-48 \mathrm{~h}$. Nematodes reproduce within the cadaver, and large numbers of IJs escape into the soil to seek additional hosts.

Heterorhabditis marelatus occurs along the Pacific coast from the San Francisco Bay area (D. Strong, pers. comm.) to at least southern Washington (personal observation). Populations occur in sandy soils under vegetation, usually behind the dunes of sandy beaches, and up to a few hundred metres inland. On the Pacific coast their habitat is subdivided into what is essentially a linear series of habitat islands separated by stretches of rocky shoreline. Here we refer to the nematodes inhabiting a continuous stretch of suitable habitat (usually a discrete beach) as a population.

Like most nematodes, Heterorhabditis have minimal powers of dispersal on their own. Gene flow on a regional scale will depend on the opportunities for nematodes to be transported either in infected hosts, phoretically (by hitching a ride on nonparasitized hosts), or passively through the movement of wind and water. Infective juveniles are susceptible to UV light and to desiccation, so they cannot be exposed to the air for long (Downes \& Griffin, 1996; Strong et al., 1996). Heterorhabditis are tolerant of salt water, so movement along shore by ocean currents might occur in coastal species like H. marelatus (Griffin et al., 1994). Transport in infected insects is possible, but heterorhabditids specialize on buried insects (as opposed to insects walking on the soil surface), and hosts are killed rapidly following infection. Thus, the first prediction is that gene flow is very restricted on a regional scale.

We also predict that $H$. marelatus populations will have small effective sizes, for two reasons. First, on a local scale (a few to tens of metres) the distribution of nematodes is very clumped and patchy, and patches go extinct and are recolonized at high rates (Stuart \& Gaugler, 1994; Strong et al., 1996). Secondly, it is likely that each patch consists of very closely related individuals descended from one or a few maternal founders. An infective juvenile that enters a host must reproduce hermaphroditically. Its offspring then mature into separate males and females who reproduce for one or more generations before producing infective juveniles that leave the host. A single infection can produce hundreds of thousands of IJs, and these tiny nematodes cannot move far on their own. Thus, patches probably contain the descendants of one or a few maternal founders. This sort of metapopulation patch structure should result in very small mitochondrial effective sizes within populations (McCauley, 1991; Caballero \& Hill, 1992; Harrison \& Hastings, 1996).

Therefore, H. marelatus should show lower overall genetic diversity, and a more strongly subdivided genetic structure, than obligately outcrossing parasites of mobile vertebrates, such as the trichostrongylids. To test this hypothesis, we used mtDNA sequence data to describe the genetic structure of $H$. marelatus populations along the Pacific coast of California and Oregon, and compared these data to the data from trichostrongylids (for which the same gene and sampling scheme were used, making the two datasets directly comparable).

\section{Materials and methods}

To describe population structure in $H$. marelatus, we sequenced $474 \mathrm{bp}$ of the $3^{\prime}$ end of the mitochondrial ND4 gene. ND4 codes for a membrane spanning polypeptide of the hydrophobic subunit of NADH dehydrogenase complex I, and has been shown to be an excellent marker for population genetics studies in nematodes (Blouin et al., 1998). We sequenced each of nine or 10 individuals per population, in six populations from coastal Oregon and California (Fig. 1). At each site we collected soil samples from an area spanning several hectares. We baited each soil sample with waxworms (Galleria mellonella), and isolated a single first generation hermaphroditic nematode from infected hosts. To avoid sampling related individuals from the same patch of soil, we made sure that no samples were taken any closer than several metres apart, and sequenced only one individual per soil sample. This region of the ND4 gene was used so that the results could be directly compared to those of Blouin et al. (1995), who used the same gene and sample sizes to study the genetic structures of four species of trichostrongylid nematodes that parasitize ruminants in North America. Here the geographical scale over which we sampled H. marelatus populations (Oregon and northern California) is about the same as that over which populations of two of the trichostrongylids were sampled (south-eastern U.S. for Mazamastrongylus odocoilei and Haemonchus placei), and is smaller than 


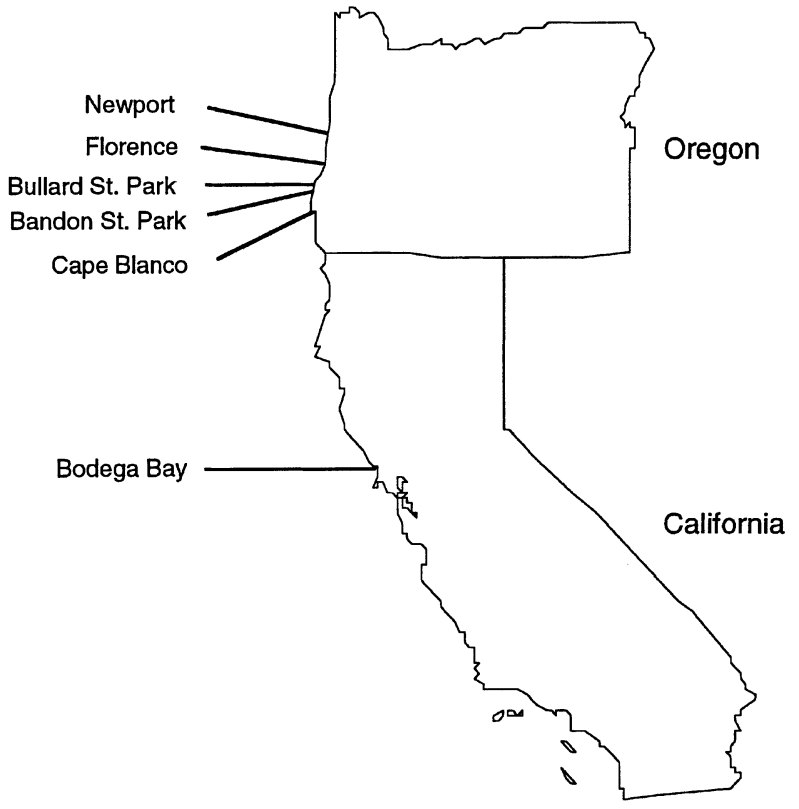

Fig. 1 Sampling sites. Partial ND4 gene sequences in Heterorhabditis marelatus were obtained from nine or 10 nematodes from each site (Table 1).

the scale over which populations of the other two were sampled (entire U.S. for Haemonchus contortus and Teladorsagia circumcincta).

Individual nematodes were crushed with a pestle in $20 \mu \mathrm{L}$ of a $5 \%$ chelex solution, and incubated overnight at $55^{\circ} \mathrm{C}$. Four $\mu \mathrm{L}$ of the supernatant was used to amplify the $N D 4$ region in a $25-\mu \mathrm{L}$ PCR reaction $(1.5 \mathrm{~mm} \mathrm{MgCl}$, $0.3 \mu \mathrm{M}$ primers, GIBCO Taq and buffer) using a Perkin Elmer 9600 thermocycler $\left(94^{\circ} \mathrm{C}\right.$ denature for $3 \mathrm{~min}$, then 35 cycles of $94^{\circ} \mathrm{C}$ for $45 \mathrm{~s}, 54^{\circ} \mathrm{C}$ for $1 \mathrm{~min}, 72^{\circ} \mathrm{C}$ for $1.5 \mathrm{~min}$, then a 7 -min extension at $72^{\circ} \mathrm{C}$ ). The PCR product was then run on a $1 \%$ agarose gel, isolated using a Supelco GenElute spin column, and sequenced on an ABI 377 automated sequencer using the PCR primers as sequencing primers. Primers used were:

forward (mb5): 5'-GGC TGG CTT ATT ATT AAA ATT AG-3'

reverse (mb9): 5'-CAA AGA ATA ATA AAA AGA TAC CAA-3'.

\section{Results}

Heterorhabditis marelatus shows strong differentiation among populations and low genetic diversity, both within populations and in the species as a whole (Table 1). We found only four distinct haplotypes (labelled A, B, B' and $\mathrm{C}$ ) out of 58 sequences in the entire sample (Figs 2 and 3), and at most two haplotypes in any population (Table 1). This diversity was strongly structured, with $86 \%$ of the total sequence diversity
Table 1 Genetic diversity statistics for the six Heterorhabditis marelatus populations sampled

\begin{tabular}{lccc}
\hline Population & $\begin{array}{c}\text { Haplotypes } \\
\text { present }\end{array}$ & $\begin{array}{c}\text { Haplotype } \\
\text { diversity, } H\end{array}$ & $\begin{array}{c}\text { Nucleotide } \\
\text { diversity, } \pi\end{array}$ \\
\hline Newport, OR & $9 \mathrm{~A}, 1 \mathrm{~B}$ & 0.20 & 0.0051 \\
Florence, OR & $1 \mathrm{~A}, 9 \mathrm{~B}$ & 0.20 & 0.0051 \\
Bullard St.Park, OR & $8 \mathrm{~B}$, 2 B & 0.36 & 0.0007 \\
Bandon St. Park, OR & $9 \mathrm{C}$ & 0 & 0 \\
Cape Blanco St. & $9 \mathrm{~B}, 1 \mathrm{C}$ & 0.20 & 0.0038 \\
$\quad$ Park, OR & $9 \mathrm{~A}$ & 0 & 0 \\
Bodega Bay, CA & & \multicolumn{2}{c}{$F_{\mathrm{ST}}=0.78 N_{\mathrm{ST}}=0.86$} \\
\end{tabular}

'Haplotypes present' shows the numbers of each of the four haplotypes (A, B, B' and C; see Figs 2 and 3) observed in each population. Haplotype diversity, $H=n\left(1-\sum x_{i}^{2}\right) /(n-1)$, where $x_{i}$ is the frequency of the $i$ th haplotype and $n$ is the sample size in each population. Nucleotide diversity, $\pi$, is the average number of substitutions per site between pairs of haplotypes in each sample. $N_{\mathrm{ST}}$ was calculated following Lynch \& Crease (1990). $F_{\mathrm{ST}}=$ $\left(H_{\mathrm{T}}-H_{\mathrm{S}}\right) / H_{\mathrm{T}}$, where $H_{\mathrm{S}}$ is the average haplotype diversity in the populations, and $H_{\mathrm{T}}$ is the haplotype diversity for the sample as a whole $\left(H_{\mathrm{T}}\right.$ and $H_{\mathrm{S}}$ calculated as for $H$ above).

$\left(N_{\mathrm{ST}}\right.$; Lynch \& Crease, 1990) and $78 \%$ of the haplotype diversity $\left(F_{\mathrm{ST}}\right)$ distributed among populations (Table 1). Even the two closest populations (Bandon, OR, and Bullard, OR, 8 km apart; Fig. 1) had no haplotypes in common, and the only private allele (Slatkin, 1985) in the sample had a frequency of $8 / 10$ in its population. Note also that this most geographically restricted allele (allele $\mathrm{B}^{\prime}$ ) also appears to be the most recently derived of the four haplotypes (Fig. 3a), and that it occurs in a population with its parent allele (allele B; Table 1). This pattern is exactly what one expects under restricted gene flow, because the geographical range of a haplotype should be strongly correlated with its age (Templeton et al., 1995). Finally, the distribution of pairwise sequence differences in $H$. marelatus clearly differs from that expected in a single population under drift-mutation equilibrium, there being too few haplotypes, given the distances among them (Fig. 3b; Tajima's $D=3.12$, $P<0.01$; Tajima, 1989). Assuming neutrality, this pattern is again consistent with historical subdivision of the species into isolated units.

\section{Discussion}

\section{Drift and gene flow in $\mathrm{H}$. marelatus}

The above results are all consistent with the small effective population sizes and low rates of gene flow predicted by the life cycle of $H$. marelatus. That there are too few haplotypes given the large genetic distances between them is interesting. A selective sweep cannot be 


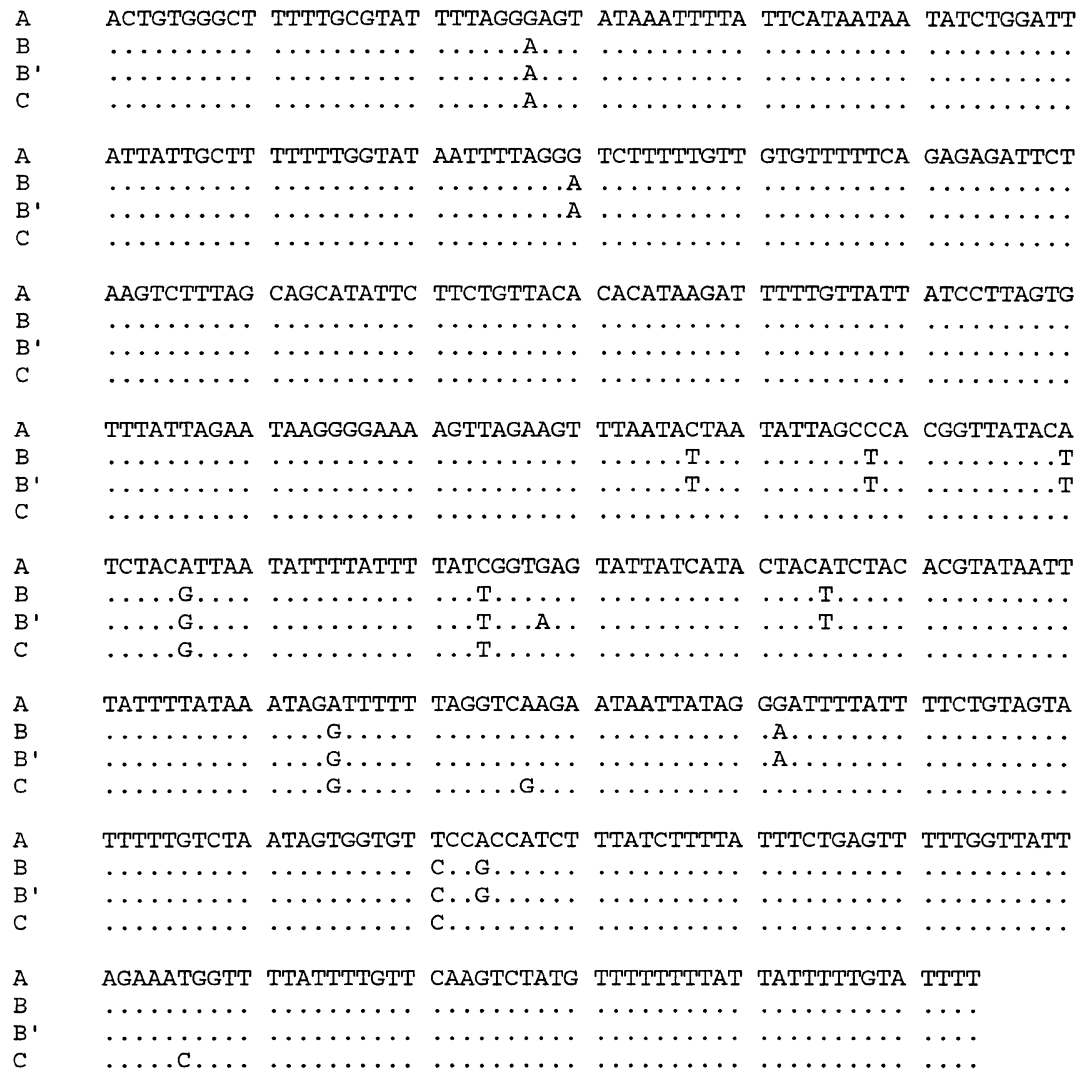

Fig. 2 Alignment of the four ND4 haplotypes observed in Heterorhabditis marelatus. All polymorphisms are in silent sites, except for the substitution in position 268 that separates haplotype $\mathrm{B}^{\prime}$ from haplotype B. ruled out, but rapid drift within populations, combined with occasional long-distance gene flow, could produce the same pattern. That two common alleles (A and $\mathrm{B}$ ) are widespread throughout the species' range, whereas even adjacent populations can be fixed for different alleles, is consistent with this scenario. Perhaps migration occurs in an isolation-by-distance fashion on land, and occasionally over long distances via ocean currents. More intensive sampling of populations throughout the range of the species might well reveal more haplotypes, but the overall pattern of strongly restricted gene flow on a local scale, with widespread common alleles, is unlikely to change.

\section{Practical applications}

Heterorhabditis spp. are extensively studied for their biocontrol abilities, and there is great interest in finding new strains that differ in characters such as host-seeking behaviour, environmental tolerance and ability to control different pests (Bedding et al., 1983; Kung \& Gaugler, 1991; Gaugler et al., 1997). Their symbiotic bacteria are equal partners in killing insects, and trait variation in the bacteria may be as or more important than in the nematodes. For example, the toxins produced by Photorhabdus spp. are some of the most potent insect killers known, rivalling the well-known Bacillus thuringensis toxin, and different species and strains of
Photorhabdus carry different toxins (Bowen et al., 1998). Consequently, there is also a major impetus to search for and characterize new strains of symbiotic bacteria, particularly those adapted to unusual hosts or habitats. Nevertheless, surprisingly little work has been carried out on the basic ecology and genetics of Heterorhabditis or their bacteria in nature (Gaugler \& Kaya, 1990; Strong et al., 1996; Gaugler et al., 1997). Ours are the first data on genetic structure in a heterorhabditid, and there has been no population genetic work on Photorhabdus. Because the symbiotic bacteria can presumably only disperse in association with their nematode, their population genetic structure should mirror that of the nematode. As part of an unrelated study we recently sequenced $616 \mathrm{bp}$ of the bacterial $16 \mathrm{~S}$ gene of bacterial isolates from each of five nematodes from Florence, OR, and from five nematodes from Newport, OR $(\approx 80 \mathrm{~km}$ apart; Fig. 1) (unpubl. data). Isolates from the two populations were fixed for different 16S rRNA haplotypes. Although these data are anecdotal, they suggest that the nematode and their symbiotic bacterium may both have population genetic structures that promote genetic drift and the opportunity for local adaptation over short distances. Thus it may be fruitful to search for useful new strains of nematode and bacteria (i.e. those adapted to unique hosts or environmental conditions) over very small geographical scales. 
(a)

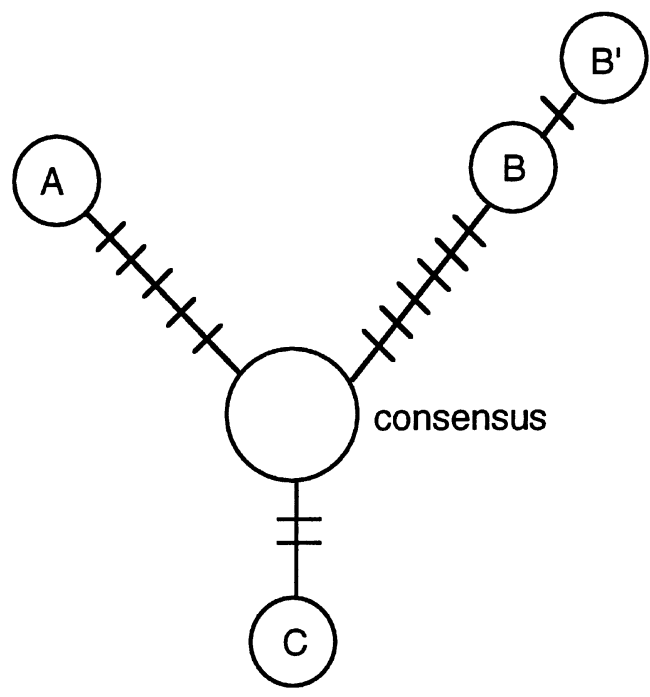

(b)

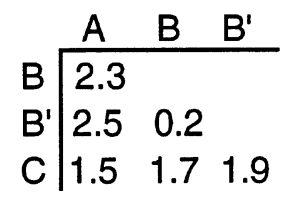

Fig. 3 (a) Network tree showing number of substitutions separating each Heterorhabditis marelatus haplotype from the consensus sequence. All substitutions in each branch are unique to that branch. (b) Percentage of sequence difference between haplotypes.

\section{Comparison with other nematode species}

Table 2 confirms the prediction that $H$. marelatus has lower overall diversity (both species-wide and within individual populations) and a more strongly subdivided genetic structure than the trichostrongylids. Only four unique haplotypes were found in 58 sequences from $H$. marelatus, whereas samples of 40 trichostrongylid sequences yielded 31-39 unique haplotypes. Within populations the haplotype and nucleotide diversity is almost an order of magnitude greater in the trichostrongylids than in $H$. marelatus, and a much greater proportion of the total sequence diversity is distributed among populations in $H$. marelatus. Because the geographical scale over which $H$. marelatus populations were sampled is smaller than that over which some of the trichostrongylids were sampled, the higher $F_{\mathrm{ST}}$ in $H$. marelatus is even more striking. Within each of the four trichostrongylid species Tajima's $D$ is not significantly different from zero, indicating tree topologies that are not significantly different from that expected under neutrality in a single population (see figs 2,3,4,5 in Blouin et al., 1995, for haplotype trees). So in these species we do not see the signature of historical subdivision into isolated populations that is apparent in the tree of $H$. marelatus haplotypes.

In the trichostrongylids vs. $H$. marelatus we see two extremes in a spectrum of genetic structures. Trichostrongylids show levels of mtDNA variation that are greater than those typically seen in other taxa, and the species that infect livestock show exceptionally high rates of gene flow over vast geographical areas (Blouin et al., 1995; also M. Blouin, S. Richter and E. Hoberg, unpubl. data on Teladorsagia circumcincta from Iceland vs. North America; C. Constant, unpubl. data on Ostertagia ostertagi from Australia vs. North America). In contrast, $H$. marelatus shows very low variation within populations and in the species as a whole, and very restricted gene flow on a small scale. In these respects the genetic structure of $H$. marelatus may be more similar to that of parthenogens such as Meloidogyne spp. than to that of outcrossing parasites

Table 2 Within- and between-population genetic diversity statistics compared between trichostrongylid species and Heterorhabditis marelatus. Both studies used the same region of the ND4 gene and sample sizes of 9-11 individuals per population

\begin{tabular}{|c|c|c|c|c|c|}
\hline \multirow[b]{2}{*}{ Taxon } & \multirow[b]{2}{*}{$\begin{array}{l}\text { Total indiv. } \\
\text { sampled }\end{array}$} & \multirow[b]{2}{*}{$\begin{array}{l}\text { Number unique } \\
\text { haplotype }\end{array}$} & \multicolumn{2}{|c|}{ Within-pop. diversity } & \multirow[b]{2}{*}{$N_{\mathrm{ST}}$} \\
\hline & & & $\begin{array}{l}\text { Average haplotype } \\
\text { diversity }\end{array}$ & $\begin{array}{l}\text { Average nucleotide } \\
\text { diversity }\end{array}$ & \\
\hline \multicolumn{6}{|l|}{ Trichostrongylidae } \\
\hline Haemonchus contortus & 40 & 37 & 1.00 & 0.023 & 0.01 \\
\hline Haemonchus placei & 40 & 31 & 0.98 & 0.019 & 0.04 \\
\hline Teladorsagia circumcincta & 40 & 39 & 1.00 & 0.024 & 0.02 \\
\hline Mazamastrongylus odocoilei & 51 & 49 & 0.99 & 0.028 & 0.31 \\
\hline \multicolumn{6}{|l|}{ Heterorhabditidae } \\
\hline Heterorhabditis marelatus & 58 & 4 & 0.16 & 0.002 & 0.86 \\
\hline
\end{tabular}

Diversity measures calculated as in Table 1.

(c) The Genetical Society of Great Britain, Heredity, 83, 253-259. 
of vertebrates. For example, only six unique mtDNA haplotypes were found in 48 Meloidogyne individuals sampled from throughout the eastern half of Australia (data from RFLP of entire mtDNA; Hugall et al., 1994). Individual Meloidogyne samples were spread over a wide geographical area in that study, so we cannot directly compare levels of within- and between-population diversity in Meloidogyne spp. to that in H. marelatus or the trichostrongylids. However, a testable prediction is that the distribution of mtDNA diversity within and among populations in Meloidogyne will be most similar to that in Heterorhabditis.

Here we designed a study to compare the genetic structures of two groups of nematodes, by using the same molecular marker and similar sampling schemes. Obviously more comparative data such as these are needed before we can generalize about the effects of life cycle on genetic structure in nematodes. In particular, we need data on species in 'natural' habitats (i.e. species that are not human associates). To our knowledge, there are no data on genetic structure in any free-living species, and of the parasitic species, only three are not parasites of humans or their domesticated plants or livestock (these include the present data on $H$. marelatus, mtDNA data on Mazamastrongylus odocoilei, which is a parasite of deer [Blouin et al., 1995], and allozyme data on Anisakid nematodes of fish and cetaceans [e.g. Paggi et al., 1991; Nascetti et al., 1993;]). Clearly this is a wide-open field of study that deserves more attention.

\section{Acknowledgements}

Thanks to D. Strong, J. Johnston, G. Poinar and D. Anderson for help collecting samples, and to A. Rabe, K. Monsen and A. Giese for comments on an earlier draft. This work was supported by the OSU Agricultural Research Foundation and by U.S. Department of Agriculture CSREES 96-34354-3072 through the Oregon State University Center for Gene Research and Biotechnology.

\section{References}

ANDERSON, T. J. C., ROMERO-ABAL, M. E. AND JAENIKE, J. 1995. Mitochondrial DNA and Ascaris microepidemiology: the composition of parasite populations from individual hosts, families and villages. Parasitology, 110, 221-229.

ANDERSON, T. J. C., BLOUIN, M. S. AND BEECH, R. N. 1998. Population biology of parasitic nematodes: applications of genetic markers. Adv. Parasitol., 41, 219-283.

BABIKER, H. A. AND WALliKeR, D. 1997. Current views on the population structure of Plasmodium falciparum: implications for control. Parasitol. Today, 13, 262-267.
BEDDING, R. A., MOLYNEUX, A. S. AKHURST, R. J. 1983. Heterorhabditis spp., Neoaplectana spp. and Steinernema kraussei: interspecific and intraspecific differences in infectivity for insects. Exp. Parasitol., 55, 249-257.

Blair, D., AGAtsuma, T., WATANOBE, T., OKAMoto, M. AND ITO, A. 1997. Geographical genetic structure within the human lung fluke, Paragonimus westermani, detected from DNA sequences. Parasitology, 115, 411-417.

BLOUIN, M. S., YOWELl, C. A., COURTNEY, C. H. AND DAME, J. B. 1995. Host movement and the genetic structure of populations of parasitic nematodes. Genetics, 141, 1007-1014.

BLOUIN, M. S., YOWELL, C. A., COURTNEY, C. H. AND DAME, J. B. 1998. Substitution bias, rapid saturation, and the use of mtDNA for nematode systematics. Mol. Biol. Evol., 15, 1719-1727.

BOWEN, D., ROCHELEAU, T. A., BLACKBURN, M., ANDREEV, O., GOLUBEVA, E., BHARTIA, R. AND FFRENCH-CONSTANT, R. H. 1998. Insecticidal toxins from the bacterium Photorhabdus luminescens. Science, 280, 2129-2132.

CABAllero, A. AND HILl, W. G. 1992. Effective size of nonrandom mating populations. Genetics, 130, 909-916.

DAY, K. P., KOELLA, J. C., NEE, S., GUPTA, S. AND READ, A. F. 1992. Population genetics and dynamics of Plasmodium falciparum: an ecological view. Parasitology, 104, S35-S52.

DOWNES, M. J. AND GRIFFIN, C. T. 1996. Dispersal behaviour and transmission strategies of the entomopathogenic nematodes Heterorhabditis and Steinernema. Biocontrol Sci. Technol., 6, 347-356.

DYBDAHL, M. F. AND LIVELY, C. M. 1996. The geography of coevolution: comparative population structures for a snail and its trematode parasites. Evolution, 50, 2264-2275.

GAUGLER, R. AND KAYA, H. K. 1990. Entomopathogenic Nematodes in Biological Control. CRC Press, Boca Raton, FL.

GAUGleR, R., LEWIS, E. AND STUART, R. J. 1997. Ecology in the service of biological control: the case of entomopathogenic nematodes. Oecologia, 109, 483-489.

GRIFFIN, C. T., FINNEGAN, M. M. AND DOWNES, M. J. 1994. Environmental tolerances and the dispersal of Heterorhabditis - survival and infectivity of European Heterorhabditis following prolonged immersion in seawater. Fund. Appl. Nematol., 17, 415-421.

HARRISON, S. AND HASTINGS, A. 1996. Genetic and evolutionary consequences of metapopulation structure. Trends Ecol. Evol., 11, 180-183.

HUGALL, A., MORITZ, C., STANTON, J. AND WOLSTENHOLME, D. R. 1994. Low but strongly structured mitochondrial DNA diversity in root knot nematodes (Meloidogyne). Genetics, 136, 903-912.

HUGHES, J. B., DAILY, G. C. AND EHRLICH, P. R. 1997. Population diversity: its extent and extinction. Science, 278, 689-692.

KUNG, S.-P. AND GAUGLER, R. 1991. Effects of soil temperature, moisture, and relative humidity on entomopathogenic nematode persistence. J. Invert. Pathol., 57, 242-249.

LYMBERY, A. J., THOMPSON, R. C. A. AND HOBBS, R. P. 1990. Genetic diversity and genetic differentiation in Echinococcus granulosus (Batsch, 1786) from domestic and sylvatic hosts on the mainland of Australia. Parasitology, 101, 283-289.

LYNCH, M. AND CREASE, T. J. 1990. The analysis of population survey data on DNA sequence variation. Mol. Biol. Evol., 7, 377-394. 
MCCAULEY, D.E. 1991. Genetic consequences of local population extinction and recolonization. Trends Ecol. Evol., 6, 5-8.

NASCETTI, G., CIANCHI, R., MATTIUCCI, S., D'AMELIO, S., ORECCHIA, P., PAGgI, L. ET AL. 1993. Three sibling species within Contracaecum osculatum (Nematoda, Ascaridida, Ascaridoidea) from the Atlantic Arctic-Boreal region: reproductive isolation and host preferences. Int. J. Parasitol., 23, 105-120.

PAGGI, L., NASCETTI, G., CIANCHI, R., ORECCHIA, P., MATTIUCCI, S., D’Amelio, S. ET AL. 1991. Genetic evidence for three species within Pseudoterranova decipiens (Nematoda, Ascaridida, Ascaridoidea) in the North Atlantic and Norwegian and Barents Seas. Int. J. Parasitol., 21, 195-212.

SLATKIN, M. 1985. Rare alleles as indicators of gene flow. Evolution, 39, 53-65.

STRONG, D. R., KAYA, H. K. AND MARON, J. L. 1996. Entomopathogenic nematodes: natural enemies of root-feeding caterpillars on bush lupine. Oecologia, 108, 167-173.
STUART, R. J. AND GAUGLER, R. 1994. Patchiness in populations of entomopathogenic nematodes. J. Invert. Pathol., 64, 39-45.

TAJIMA, F. 1989. Statistical method for testing the neutral mutation hypothesis by DNA polymorphism. Genetics, 123, 585-595.

TEMPleton, A. R., ROUTMAN, E. AND PHILlips, C. A. 1995. Separating population structure from population history: a cladistic analysis of the geographical distribution of mitochondrial DNA haplotypes in the tiger salamander, Ambystoma tigrinum. Genetics, 140, 767-782.

TIBAYRENC, M., KJELlBERG, F., ARNAUD, J., OURY, B., FRÉDÉRIQUE BReniÈRE, S., DARDÉ, M.-L. AND AYAlA, F. J. 1991. Are eukaryotic microorganisms clonal or sexual? A population genetics vantage. Proc. Natl. Acad. Sci. U.S.A., 88, 51295133. 